Nancy Ramacciotti de Oliveira-Monteiro ${ }^{\mathrm{a}}$ (iD) https://orcid.org//0000-0002-8963-5162

Gustavo Cardoso Luz Peterlevitz ${ }^{\mathrm{a}}$ iD https://orcid.org/0000-0002-0130-8926

Rodolfo Eduardo Scachetti ${ }^{\mathrm{a}}$

(iD) https://orcid.org/0000-0002-7575-5745

aUniversidade Federal de São Paulo (Unifesp) - Bacharelado Interdisciplinar em Ciência e Tecnologia do Mar. Santos, SP, Brasil.

Contato: Nancy Ramacciotti de Oliveira-Monteiro

E-mail: nancy.unifesp@gmail.com

Os autores declaram que o trabalho não foi subvencionado e que não há conflitos de interesses.

Trabalho baseado na monografia de graduação em Bacharelado Interdisciplinar em Ciência e Tecnologia do Mar intitulada Vida no mar: estudo de relatos online de trabalhadores embarcados, de Gustavo Cardoso Luz Peterlevitz, defendida em 2015 na Unifesp (Baixada Santista) e apresentado no XXIII Congresso de Iniciação Científica da mesma universidade (2015).

\section{Queixas e benefícios associados ao trabalho embarcado: relatos on-line de trabalhadores de cruzeiros marítimos}

\author{
Complaints and benefits concerning work on board: \\ cruise ship workers' online reports
}

\begin{abstract}
Resumo
Introdução: as pesquisas brasileiras sobre condições do trabalho embarcado abordam sobretudo o trabalho offshore, em plataformas marítimas. Estudos sobre a qualidade de vida dos trabalhadores de cruzeiros marítimos são pouco encontrados, provavelmente devido às dificuldades de acesso a essa atividade. Objetivo: identificar e descrever condições de trabalho e de vida no mar de trabalhadores de cruzeiros marítimos embarcados, a partir de suas percepções relatadas em blogs. Métodos: estudo qualitativo baseado na netnografia (etnografia digital), uma metodologia de caráter etnográfico aplicada em estudos de ambientes e fontes digitais. As informações foram levantadas em 23 blogs e sistematizadas com base na análise de conteúdo. Resultados: foram definidas duas categorias temáticas: uma de queixas e outra de benefícios associados ao trabalho embarcado. As queixas mais relatadas foram: falta de conforto, problemas de saúde, estados psicológicos negativos e falhas na organização do trabalho; e os benefícios mencionados foram salário, oportunidades de viagem e socialização facilitada. Conclusão: apesar de algumas limitações, as investigações baseadas em relatos on-line permitiram identificar e analisar as condições de trabalho e de vida associadas aos trabalhadores embarcados.
\end{abstract}

Palavras-chave: trabalho embarcado; relatos de experiências em ambientes virtuais; etnografia virtual; cruzeiros marítimos, saúde do trabalhador.

\begin{abstract}
Introduction: Brazilian research on maritime work conditions concerns mainly the work on offshore platforms. Studies on the quality of life of cruise ship workers are not easily found, probably because these workers and their offshore activities are little accessible. Objective: to identify and describe cruise ship workers' working and living conditions, through their perceptions reported on blogs. Methods: qualitative study based on netnography (digital ethnography), an ethnographic methodology applied to analysis of environments and digital sources. Data was collected through 23 blogs, and systematized according to content analysis. Results: two thematic categories were defined, one referring to complaints and the other to offshore work benefits. The most reported complaints were: lack of comfort, health problems, negative psychological states and failures in work organization. Mentioned benefits were: salary, travel opportunities and facility in socializing. Conclusion: despite some limitations, investigations based on online reports made it possible to identify and analyze offshore working and living conditions.
\end{abstract}

Keywords: work on board; reports of experiences in virtual environments; virtual ethnography; cruises; occupational health. 


\section{Introdução}

O Brasil é um país de dimensão continental, com uma zona costeira de $8.500 \mathrm{~km}^{1}$, condição muito favorável a viagens turísticas ${ }^{2}$. Empresas de cruzeiros marítimos contratam muitos funcionários, de diferentes áreas de formação e condições de escolaridade. Esses trabalhadores têm jornadas de trabalho peculiares, muitas vezes operando em desvio de função ${ }^{3}$.

Devido à carência de pesquisas voltadas a essa classe, os estudos sobre o trabalho offshore, especialmente a exploração e produção de petróleo e gás, se tornam subsídios oportunos para este estudo, pois oferecem referências pertinentes ao trabalho no mar. Apesar de a satisfação pessoal no trabalho ser um elemento subjetivo e, logo, permeável a mudanças por motivos físicos e psicológicos ${ }^{4}$, a insatisfação pessoal é muito ressaltada nos estudos com trabalhadores offshore ${ }^{5-7}$, e pesquisas brasileiras sobre o assunto apontam uma série de problemas na área. Um dos problemas elencados, por exemplo, é a alterações da percepção temporal por causa da estadia no mar, vista como penosa e difícil, ao contrário do tempo passado em terra, descrito como dinâmico e positivo ${ }^{5,7}$.

O confinamento, próprio do trabalho offshore, também é aludido, pela limitação do espaço e pelo impedimento no "ir e vir" dos trabalhadores, além do isolamento social e da ausência de privacidade ${ }^{8}$. A ansiedade também é comum, refletindo-se no trabalho e também na vida familiar ${ }^{9}$. Assim, conforme Seligmann-Silva, Bernardo, Maeno e Kato ${ }^{10}$, as condições do trabalho offshore podem trazer muitas consequências negativas, tanto físicas quanto psicoativas.

O confinamento offshore é marcado pela restrição e afastamento de fontes de entretenimento (como família, lazer e amizades) ${ }^{8,11}$, condições estas que se aproximam do conceito de "instituições totais", de Erving Goffman, ou seja, locais delimitados onde tudo está sob o controle de terceiros, com submissão a regras rígidas e hierarquização de poder, como se vê em manicômios, prisões e conventos ${ }^{12}$.

Nos navios de cruzeiro, esse confinamento pode ser comparado com o trabalho nas plataformas de petróleo. Por exemplo, o Repórter Brasil ${ }^{13}$ noticiou o resgate de 11 tripulantes, em Santos (SP), após uma fiscalização do Ministério do Trabalho e Emprego (MTE). Embora o caso seja muito específico, percebe-se com ele fragmentos de um mundo de trabalho problemático, onde se pode unir o luxo dos viajantes à precarização do trabalho e mesmo à possibilidade de exploração de funcionários.
Nas alternativas para lazer dos viajantes de turismo, navios de cruzeiro oferecem vários espaços que estimulam a diversão e o uso de bebidas alcoólicas, o que pode facilitar seu consumo (e de outras substâncias psicoativas) pelos próprios trabalhadores. O confinamento não permite clara discriminação entre ambientes e períodos de trabalho e de folga e, além disso, o estresse laboral aumenta o risco de acidentes e favorece o aumento da probabilidade do uso de drogas ${ }^{14-16}$. Um estudo sobre a qualidade do trabalho na área de saúde, por exemplo, mostrou aumento no consumo de álcool e de substâncias psicoativas em trabalhadores da enfermagem que referiam seu trabalho como "contínuo, desgastante e exaustivo"16.

Pesquisar o trabalho offshore não é simples, seja pela necessidade de autorização das empresas envolvidas, seja pelas dificuldades impostas pelo próprio confinamento. Em pesquisas análogas, a netnografia (ou etnografia digital) é uma opção metodológica favorável.

A utilização da netnografia vem sendo estudada pela comunidade científica como opção metodológica desde sua concepção ${ }^{17}$. Rocha e Montardo ${ }^{18}$ colocam que muitos objetos de estudo podem ser localizados em um "ambiente virtual" - internet - por favorecer relatos de experiências cotidianas ${ }^{19}$. $\mathrm{Na}$ etnografia tradicional, o pesquisador precisa estar presente fisicamente no campo de estudo ${ }^{17}$, isto é, num recorte de mundo e por um determinado tempo, o que não ocorre na netnografia.

Caracterizada como metodologia qualificativa, a netnografia é a fusão de técnicas etnográficas tradicionais com a nova atmosfera digital, e sistematiza informações que o próprio usuário cede ao meio digital. Essa "blogosfera" também pode ser definida como contexto cultural, pois é útil para a etnografia, método utilizado para tentar entender diferentes culturas $^{20}$.

Como a etnografia prevê que o pesquisador interaja com as pessoas pesquisadas, a netnografia, em sentido stricto, seria uma interação digital entre pesquisador e pesquisados, baseada, por exemplo, em redes sociais; já em sentido lato, adotado neste estudo, a interação acontece pelo fato de o pesquisador também navegar na internet. A netnografia é encontrada em trabalhos relacionados a culturas digitais, como o estudo de Herrera e Passerino ${ }^{21}$ sobre o estigma de portadores de deficiência visual e sua interação no meio digital; ou o de Brüggemann e Bitencourt $^{22}$, com jovens futebolistas brasileiros que atuam em times europeus, analisando o papel das redes sociais na preservação do vínculo desses atletas com a cultura e a identidade brasileira.

Di Felice, Torres e Yanaze ${ }^{23}$ sublinharam os principais traços da nova geometria comunicacional 
criada com as redes digitais interativas. Os autores destacam que no mundo contemporâneo as pessoas deixam de ser apenas receptoras de informação, passando a produtoras também, de forma menos jornalística ou científica e mais pessoal e subjetiva.

Voltando ao trabalho offshore, com base no estudo de Sifry ${ }^{24}$, que indicou grande aumento no número de blogs ampliando os espaços de socialização na internet, nota-se que os textos publicados on-line, através de notebooks, tablets ou mesmo smartphones, facilitam a criação de diários de bordo e relatos pessoais.

Para Recuero ${ }^{25}$, blogs geralmente têm características informais e abordam conteúdos pessoais, mesmo que seus autores possam propor escritos de outra natureza, como os blogs mais informativos. Ele apresenta uma classificação de blogs, numa subdivisão de "diários eletrônicos", "publicações eletrônicas" e "publicações mistas". Os primeiros trazem pensamentos e fatos da vida pessoal do autor, servindo como seu canal de expressão; as "publicações eletrônicas" são voltadas predominantemente para a informação, com notícias e comentários sobre determinados assuntos baseados no tema do blog (como cultura pop, música, tecnologia, esportes etc.). Por fim, "publicações mistas", como o nome sugere, combinam as características dos dois anteriores ${ }^{25}$.

Nesse contexto, esta pesquisa objetivou identificar e descrever condições de trabalho e de vida no mar de trabalhadores de cruzeiros marítimos embarcados, a partir de suas percepções relatadas em blogs.

\section{Métodos}

Estudo qualitativo com base em etnografia digital (netnografia). Foram investigados blogs com "perfil A", definido por Recuero ${ }^{25}$ como "diários eletrônicos”. A análise abarcou blogs de 23 participantes, trabalhadores de cruzeiros marítimos, do site blogstripulantes.blogspot.com.br, o único em língua portuguesa encontrado com esse conteúdo (em setembro de 2014, época em que este estudo foi planejado). Esses sujeitos e seus 23 blogs foram selecionados por ordem cronológica de postagem, sendo considerados os sujeitos/blogs das primeiras 30 postagens de cada blog. Esse número foi fixado por critério de conveniência, caracterizando o estudo como não probabilístico e com amostra intencional. O período de abrangência total de postagens analisadas foi de agosto de 2011 a agosto de 2015 .

Os dados foram sistematizados por categorias temáticas seguindo a análise de conteúdo proposta por Bardin ${ }^{26}$ : após uma leitura analógica e progressiva dos blogs foi possível encontrar as categorias iniciais, que foram reagrupadas em subcategorias de sentido mais genéricas.

Na apresentação dos resultados, além da exposição das frequências das categorias, foram reproduzidos trechos considerados exemplificativos para as temáticas abordadas. Destaca-se que não houve, seguindo os preceitos da análise de conteúdo aqui empregada, alterações nos textos dos relatos e nas formas expressivas, apenas erros de digitação, pontuação, falta de acentuação e problemas de ortografia ou excessiva abreviação foram revisados, com o intuito de favorecer a leitura. Por cuidados éticos, nomes de pessoas foram abreviados, e de empresas, omitidos. Marcas de produtos foram descaracterizadas.

Este estudo foi aprovado pelo Comitê de Ética em Pesquisa da Universidade Federal de São Paulo (Unifesp), sob o parecer CEP/Unifesp $\mathrm{n}^{\circ}$ 1.094.035.

\section{Resultados}

O contato com os blogs revelou uma realidade de conteúdos muito diversificada, e nem todos os "diários eletrônicos" traziam dados exatos sobre a função ou idade do autor. Em sua maioria foram identificados adultos jovens: nove (39\%) dos indivíduos, não forneceram informações sobre a idade; oito (35\%) manifestaram estar na faixa de 20 a 25 anos, cinco (21\%), de 26 a 30anos, e apenas um (5\%) estava acima dessa idade, com 33 anos. Todos os trabalhadores cujos blogs foram analisados identificaram seu gênero de alguma forma, podendo ser depreendido pelo nome adotado na postagem e outros indicativos. Foram 15 os blogs com identificação do gênero feminino (65\%) e oito com identificação de gênero masculino (35\%).

Essas condições caracterizavam, a princípio, um universo de levantamento pouco consistente. Após leituras exaustivas dos conteúdos dos blogs, com uso da análise de conteúdo, uma proposta de sistematização emergiu, apontando dois eixos temáticos que permeavam as postagens: um relativo a queixas e outro a benefícios frente ao trabalho embarcado.

$\mathrm{O}$ arranjo dos temas das queixas e dos benefícios foi feito em subcategorias de agrupamento dos conteúdos.

As queixas foram agrupadas nas sete seguintes categorias:

I Falta de conforto e insalubridade: reclamações de desconforto na cabine, falta de privacidade, falhas no condicionamento ambiental da temperatura, espaços apertados, baixa qualidade da alimentação (cardápios, temperos, preparação inadequada de alimentos), condições 
inadequadas de higiene pessoal, balanço do navio, barulhos e ruídos, e falhas na conexão com a internet.

II Estado psicológico negativo: relatos de ansiedade, dificuldade de adaptação às alterações marcadas por embarques ou desembarques, estresse, desmotivação, frustração, medo de acidentes, solidão, saudades da família e de amigos, e desorientações espaço-temporais.

III Dificuldades na organização do trabalho: relatos de falta de tempo, desvio de função, carga horária excessiva, instabilidade e imprevisibilidade para receber salário, e situações de abuso de poder.

IV Problemas de saúde: relatos de dores físicas, exaustão, anemia, perda de peso, sonolência e distúrbios de sono, abuso de álcool, problemas na adaptação às alterações bruscas de clima (variações pluviométricas, temperatura, umidade), e despreparo de equipes médicas.

V Preconceito: xenofobia, preconceito racial, homofobia e choques culturais (conflitos de ideias de origem cultural).

VI Sociabilidade: relatos de dificuldade nas interações sociais no navio, dificuldades de comunicação (línguas estrangeiras e desconhecidas) e instabilidade em relacionamentos interpessoais.

VII Outros: problemas com furtos no navio.

Por sua vez, os relatos referentes aos benefícios foram sistematizados em duas subcategorias gerais:

I Sociabilidade no navio: momentos festivos, companheirismo e amplitude no número de parceiros sexuais.

II Elogios sobre a qualidade dos navios, salários e oportunidades de viagem.

Apresentamos a seguir manifestações extraídas dos blogs analisados que exemplificam a categorização definida na análise de conteúdo.

Iniciamos com o eixo temático queixas.

Queixas sobre falta de conforto e insalubridade constaram em todas as postagens analisadas, incluindo aspectos relativos a deficiências, inadequações e insatisfações em relação a:

Cabines - "tem vezes que você divide a cabine com mais quatro caboclos, e um só chuveiro"; "a segunda (cabine) tinha janela, o que fazia toda diferença”; “'menores' empregos no navio são os cleaners e laundry men... esses funcionários normalmente moram nas cabines no piso mais baixo do navio, em cabines compartilhadas com um banheiro comum e chuveiro para ser compartilhado".

Privacidade - "privacidade é luxo para tripulação".

Alimentação - "comida péssima... com excesso de curry e pimenta"; "antes de eu embarcar, eu nunca imaginei que um dia na minha vida teria que comer escondida em um canto, e pior, que teria que pedir pra alguém roubar comida pra mim"; "fui almoçar e a comida estava horrível, tentei comer a carne, então só consegui comer mesmo pão e frios".

Higiene - "tomar banho aqui é considerado um luxo".

Conectividade - "internet no navio é cara, fora do navio quero descansar, comer, dormir... então fica meio complicado atualizar sempre o blog"; "alguns têm que contar com a sorte para poder descer do navio, usar os locutórios, que são bem baratos para contatar suas famílias, ou mesmo usar a net da[cafeteria] e mandar uma mensagem [no aplicativo de chat]".

Queixas pertinentes aos estados psicológicos, quase sempre associados às condições de confinamento, foram manifestadas na grande maioria das postagens $\left(91 \%^{\mathrm{b}}\right)$. Elas se referiam a:

Indicativos de problemas de ansiedade - "não sei quanto tempo demora para acabar essa sensação de desespero, de sair correndo para fora do navio"; "tudo começa reunindo os exames, certificados, arrumando a mala novamente e claro que tudo isso vem junto a ansiedade que todo embarque proporciona, independente de ser o primeiro ou o quarto"; "na verdade, a contagem regressiva é diária, e a ansiedade pra ir embora muito grande"; "hoje foi um dia que eu tava muito carente... carente dos abraços fortes que eu dou na minha família”.

Desorientações espaço-temporais - "vida a bordo é ligar o canal do tempo para ver se tá sol, chovendo, quente, ventando, ao invés de perguntar pra sua mãe, caso não queira abrir a janela”; "você tem que ligar a TV para ver o tempo lá fora"; "quase dois meses no navio e já perdi a conta de quantas vezes pensei em ir embora... assim como a noção de tempo, pois nunca consigo dizer qual dia do mês é"; "eu ainda estava muito perdida, não sabia onde ficavam as coisas no navio, porque na parte onde nós andamos é praticamente tudo igual, tudo branco e quase sempre não sabemos se estamos na proa ou na popa do navio".

Problemas relativos à organização do trabalho também foram bastante frequentes nas postagens dos blogs (78\%). As queixas abrangiam:

\footnotetext{
Humilhações - "humilhação acontece sim, e você tem que aprender até onde dá pra engolir e até onde tem que responder, e mesmo assim saber responder, pra sua vida não virar um inferno"; "quem reclama tem represália sim"; "além de ter que usar alguns uniformes que dão vergonha”.
}

b As porcentagens servem apenas como indicativo de aparição dos conteúdos. 
Problemas com chefia - "fomos conhecer a chief housekeeper no office, já deu aquele friozinho na barriga porque na empresa esses chefes são o cão chupando manga!"; "os italianos gesticulam muito pra falar, para mim foi assustador... e muitos ocupavam cargos de gerência”.

Problemas com salários e direitos do trabalhador “como não é um trabalho registrado, você não quer ter muito tempo de férias, já que não lhe pagam nesse período... tentei ligar algumas vezes na agência que me embarcou em Santos... não me atendiam ou davam respostas como: 'o seu nome ainda não está no sistema'... comecei a entrar em desespero"; "não era justo para alguém que havia ficado oito meses embarcado, trabalhando direto, sem nem um dia de folga sequer".

Falta de tempo, desvio de função - "sempre reforço o quanto o trabalho dentro do navio é puxado... não conseguíamos prestar atenção, tamanho era o cansaço"; "mesmo que não seja a nossa área, estamos lá trabalhando".

Hierarquia não baseada em critérios de mérito - "os postos de trabalho em um navio de cruzeiro são praticamente baseados na nacionalidade, que designa o tipo de arranjo de vida"; "o tipo de trabalho determina a hierarquia de status da tripulação"; "a hierarquia determina os privilégios da tripulação e o tipo de regras sociais não ditas que eles devem seguir”.

Queixas do campo da saúde do trabalhador apareceram em $74 \%$ dos relatos consultados, destacando-se os exemplos a seguir:

Dores físicas, falta de apetite e doenças - "um dedo de minha mão direita está inchado, com luxação no nervo, e na minha perna já está estourando um monte de nervos"; "desenvolveu anemia ao voltar de seu primeiro contrato"; "os dias estavam cada vez mais árduos com tanta dor nas 'batatas das pernas”'... houve diversas madrugadas em que eu acordei com a dor delas... a dor parecia que queimava a perna"; "sabe, minhas colegas mulheres reclamam que começaram a aparecer varizes após dois meses a bordo".

Distúrbios de sono - "dormia somente cinco horas por dia... o corpo já estava suuuper cansado”.

Abuso de álcool - "vida a bordo é ficar bêbado com menos de cinco dólares"; "eu gostava de beber, não pela bebida em si, mas pela companhia da galera enquanto se bebia... sempre bebi em terra e a bordo bebia muito mais"; "passou mal de tanto comer e beber, está lá no médico agora”; "passamos por várias coisas juntos... cuidar um do outro quando chegava bêbado na cabine, coisa que, diga-se de passagem, o R. fez mais vezes porque eu gosto de beber um pouquinho, e esse pouquinho me transforma em um outro cara, e esse outro cara bebe pra c...!!!”.

Queixas sobre preconceitos apareceram como o terceiro item de menor incidência nas postagens (26\%), como no exemplo:

"semana passada passei o dia em Lisboa e pude conhecer um pouco do preconceito que rola com brasileiros por aqui. Alguns portugueses simplesmente não nos dão informações, e outros, quando o fazem, demostram muita má vontade"; "e mesmo dentro da balada o preconceito se mostrou mais uma vez"; "eu queria te apresentar um amigo... não quero, ele é negro!”.

Queixas pertinentes à sociabilidade foram manifestadas em $17 \%$ das postagens, como:

"eu comecei a chorar na frente dela e disse que estava muito difícil, pois eu não tinha paz nem no trabalho e nem na minha cabine, falei tudo mesmo!”; "já na minha cabine a minha roommate da Ucrânia, que no início era legal, começou se achar a dona da cabine, pois chegou antes e eu tinha que seguir as regras dela, ela implicava com tudo o que eu fazia"; "quando você volta pra casa, no mundo real, você se depara com situações inusitadas, como dizendo oi e sorrindo, tipo Disney smile, para todo cidadão que passa por você!”; “é um ambiente confinado, você vai ver as mesmas pessoas todos dias... inclusive quem você não quer ver"; "os relacionamentos têm dia e hora para acabar, e não adianta se iludir que vai encontrar o príncipe encantado, isso é raro, muito raro"; "alguns casais são apenas 'namorados de navio'... como diz a A.: não passam da gangway... em determinados casos, isso é bem claro e de comum acordo"; "acho que já esqueci o que é sexo, isso sim, [fazer sexo] virou lenda”.

Queixas e referências a furtos no navio também apareceram (7\%), como nos exemplos:

\footnotetext{
"afinal, a maioria de nós foi ensinada a nunca pegar o lápis do coleguinha e muito menos roubar o lanche dele, mas a bordo a palavra 'roubar' tem variáveis"; "a máfia é muito comum a bordo, e qualquer pessoa faz, desde o capitão até o mais pobre dos crew... uma vez fui fazer a cabine do barman, e quando cheguei lá tinha uma fruteira cheia de mangas, bananas e pêssegos, umas garrafas de [bebida alcoólica] e um pote de $5 \mathrm{~kg}$ de [creme de avelã] embaixo da mesinha!... agora me digam, vocês acham que ele comprou tudo isso? Claro que não, né?... na realidade, todo mundo sabe que todo mundo rouba, mas a bordo é considerado normal quando se trata de sobrevivência".
}

Em relação ao eixo temático benefícios, as duas subcategorias definidas foram: sociabilidade no navio (associada à compensação frente à carência do contato familiar) e características positivas do trabalho em cruzeiros marítimos (qualidade dos navios, salários e oportunidade de viagens). As duas subcategorias fazem referência a momentos prazerosos, tanto os vividos com companheiros de trabalho (em ocasióes de divertimento e de maiores chances para encontros sexuais) como os provenientes das condições específicas de cruzeiros marítimos (salário conveniente, benesses do navio e realização de viagens). 
As referências a benefícios de sociabilidade foram identificadas em $78 \%$ das postagens e podem ser exemplificadas nos trechos a seguir:

\begin{abstract}
"têm uns que te levam até para socializar no Crew Bar... haha... eles são seus primeiros amigos"; "Os tripulantes parecem uma família, todo mundo se conhece, as pessoas estão sempre sorrindo e procurando te ajudar”; “ mas você sempre terá uma família a bordo!!!”; “ou seja, o cara que limpa sua cabine, ou o chefe que te pede filme pornô, seus colegas de trabalho, ou mesmo os passageiros!!!”; "você está tão longe de casa, mas parece estar cercado por sua família”; "do que eu mais gostei foi a Páscoa, quando eu e os colegas sempre organizávamos os chocolates e, claro, fazíamos a mafia dos chocolates na minha cabine... organizávamos as brincadeiras para achar os ovos com as crianças, fazíamos pintura facial também”; "o Crew Bar geral é aberto a todos os membros da tripulação... isso significa que, mesmo agrupamento dos oficiais mais bem classificados pode festejar com os 'menores' homens e mulheres, em termos de hierarquia"; "os amores a bordo são fascinantes e rápidos e rasteiros e, às vezes, avassaladores".
\end{abstract}

Benefícios relacionados a características positivas do trabalho em navios de cruzeiro foram manifestados em $69 \%$ das postagens:

\begin{abstract}
“o meu navio era o M. que é um navio intermediário na minha opinião, pois existem muitos melhores e piores na companhia... a grana era alta e os lugares onde o navio passava eram incríveis"; "apesar de ralar muito em navio, esse trabalho também te proporciona momentos como esse... mesmo assim, o melhor a fazer é descer nos portos quando possível e vislumbrar esse mundão de Deus! Era o gás que eu sempre precisava para continuar trabalhando num navio".
\end{abstract}

Por fim, um resultado a ser considerado, para além das categorias de queixas e benefícios, foi a de uma identidade profissional mais difusa e passageira: fronteiras profissionais não pareceram bem demarcadas nos relatos analisados.

\section{Discussão}

O presente estudo expôs impressões de trabalhadores de cruzeiros marítimos sobre suas experiências da vida cotidiana no mar. Foram descritos aspectos gerais de relatos on-line desses trabalhadores embarcados, observando-se indicativos de queixas e de benefícios em relação ao trabalho exercido. Adianta-se que fatores como faixa etária predominante de adultos jovens e contratação de mão de obra pouco especializada sugerem um perfil de pouca experiência por parte dos autores das mensagens.

A maior participação do gênero feminino nos blogs analisados corrobora o relatório State of blogosphere ${ }^{24}$, que apontanva um aumento no número de escritoras de "diários eletrônicos". Cerqueira, Ribeiro e Cabecinhas ${ }^{27}$ expuseram a fragilidade com que mulheres ganham espaço na cibercultura, discorrendo sobre como o sexo feminino ainda está sujeito a estereótipos. Ainda segundo o State of blogosphere ${ }^{24}$, dois terços dos autores de blog são homens (66\% de homens e 34\% de mulheres). Entretanto, se olharmos mais de perto, blogs classificados como "diários eletrônicos" são mais frequentes no gênero feminino (83\% dos blogs de mulheres são diários desse tipo, contra $76 \%$ de participação masculina).

Essa diferença de participação entre os sexos é observada por Cerqueira, Ribeiro e Cabecinhas ${ }^{27}$, que questionam a real participação e visibilidade das mulheres no meio digital, e se blogs assinados por homens podem, por conta do gênero, ter mais sucesso e reconhecimento do que blogs escritos por mulheres. Em contraponto, Abreu et al. ${ }^{28}$ mostram uma homogeneidade de gênero na utilização da web, não somente na blogosfera, mas na internet como um todo, caracterizando a utilização de sites comuns para homens e mulheres de forma igualitária (51,4\% do sexo feminino e $48,6 \%$ do sexo masculino).

Comparando os resultados, verifica-se que os dados são consistentes em relação ao cruzamento de suas categorias. Por exemplo, a valorização dos ganhos de sociabilidade como benefício próprio a esse perfil de trabalho corresponde à menor incidência dessa mesma categoria como queixa (sendo a segunda queixa menos referida). Esses dados funcionam, guardada as devidas proporções, como espelho invertido dessas categorias, ainda que isso não fosse previsto no início do desenho da pesquisa.

As queixas à infraestrutura do navio, mais precisamente das cabines, se referiam prioritariamente a dificuldades ergonômicas, especialmente durante o repouso dos trabalhadores. A cabine foi muitas vezes referida como um local apertado, abafado e "bagunçado", onde os ocupantes tinham que driblar a falta de privacidade para tentar conviver harmonicamente.

Nas queixas relacionadas a estados psíquicos, debruçando-se sobre o cotidiano do embarcado em cruzeiros e relacionando-o ao de trabalhadores nas plataformas de extração de petróleo e gás, pode-se notar coincidências em vários aspectos que Castro e Nunes ${ }^{11}$ admitem como "déficits da profissão", como os limites do "ir e vir", o distanciamento da família e o isolamento social. No mesmo quesito, o uso de álcool, muito referido nos blogs dos trabalhadores de navio, corrobora os resultados no aumento do uso de drogas por trabalhadores submetidos a estresse laboral $^{14-16}$. O uso abusivo de álcool pode estar associado 
ao mal-estar psíquico decorrente do desconforto e da insalubridade, além do fácil acesso em navios de cruzeiro.

Outro dado encontrado se referia à alimentação oferecida aos trabalhadores embarcados, sendo agrupada na categoria de insalubridade. Na $\mathrm{crew}$ mass (refeitório só para funcionários), o cardápio foi referido como diferente do servido para os passageiros. Embora possa ser comum essa separação de local de refeição para tripulantes e passageiros num navio, como também a oferta de cardápios diferentes para trabalhadores de funções diversas (oficiais, classes distintas de trabalhadores e de passageiros), queixas sobre repetição excessiva, falta de tempero e opções que desagradavam os tripulantes foram frequentes.

Voltando ao contexto offshore do trabalho de plataformas de petróleo, em relação à percepção de tempo, segundo Castro ${ }^{29}$, existe uma contagem regressiva dos dias embarcados e uma ansiedade para que a data de desembarque da plataforma petrolífera chegue. Porém, no presente estudo, a leitura dos blogs mostrou manifestações diferentes, existindo não apenas a ansiedade para desembarcar, mas também para embarcar novamente.

Em achados da literatura acerca do trabalho offshore, Leite ${ }^{8}$ assinala que esse trabalhador é envolto por prejuízos para distrações e entretenimento durante seus dias de trabalho na plataforma. Já a análise dos blogs indicou distrações prazerosas, com festas no navio e confraternização com colegas, o que tende a favorecer o acesso, conforme mencionado, a bebidas alcóolicas, por exemplo. Além disso, contrariamente a referências da literatura sobre trabalhadores de plataformas marítimas, que incluem descrições sobre abstinência sexual forçada ${ }^{6,29}$, nas postagens estudadas foram elencadas diversas possibilidades de encontros sexuais nos navios.

Sintonia entre os embarcados foi um sentimento encontrado nos blogs, mas com ausência de elementos que indicassem vínculos mais fortes de amizade, como maior confiança e laços mais profundos. Isso pode estar associado aos turnos e trocas constantes de navio, o que não favorece maior distensão temporal para uma sociabilidade menos superficial. A tendência no trabalho analisado é a multiplicação das possibilidades de socialização, mas sempre com laços frágeis. Essa condição pode indicar um estado psicológico de maior defesa emocional, diante do confinamento e da instabilidade das relações. O linguajar dos blogs, de certa forma, também parecia reproduzir comunicações igualmente efêmeras, embora com pontuais expressões emocionais mais significativas.
Cabe ressaltar que o material dos blogs trouxe pouco ou nada sobre uma identificação positiva com a ocupação e profissão de tripulante. Foram expressivas as fragilidades e/ou ausência de um sentido de pertinência a determinada categoria profissional, para além de ser tripulante de cruzeiro marítimo - condição que sobrepujou e praticamente diluiu identidades profissionais nas manifestações coletadas.

\section{Considerações finais}

Estudos sobre a qualidade de vida do trabalhador embarcado são pouco encontrados na literatura brasileira, provavelmente pelas limitações de um acesso direto a essa classe enquanto exercem suas atividades no mar. Com uma metodologia também ainda pouco referida, a netnografia, procuramos contornar esse desafio do conhecimento de condições de um grupo desses trabalhadores, a partir de suas percepções manifestadas em relatos on-line. $\mathrm{O}$ trabalho apresenta limites próprios de sua condição inovadora.

Comparar a vida do trabalhador embarcado em cruzeiro marítimo com a de um trabalhador em plataformas de extração de petróleo e gás pode, à primeira vista, indicar muitas diferenças. Entretanto, desconforto, ansiedade e falta de privacidade são condições comuns do trabalho no mar.

Os resultados apontam várias queixas relativas ao mundo de tripulantes de navios de cruzeiros, como problemas na organização do trabalho, e, especialmente o desconforto das cabines. Estas, que deveriam ser apropriadas para repouso, sono, restauro e autocuidado, foram descritas como bastante negativas.

Queixas de natureza psicológica também foram verificadas e pareceram associadas à situação de confinamento, sem contato presencial da família ou amigos. Esses limitantes apontam condições propícias para fatores de risco à saúde desses trabalhadores.

Por sua vez, os benefícios relatados concentraram-se em aspectos de lazer e desfrute. Oportunidades de viagem, festas, confraternizações, foram condições presentes nos relatos. Os cruzeiros marítimos foram criados para a diversão dos passageiros, e os trabalhadores tripulantes acabam por partilhar algumas dessas experiênciais, incluindo situações de consumo abusivo do álcool.

Sugerimos o aprofundamento e a ampliação de estudos sobre a vida do trabalho no mar, diversificada e intrigante em suas características. 


\section{Contribuições de autoria}

Todos os autores contribuiram substancialmente no desenvolvimento do estudo e na elaboração e aprovação do texto publicado.

\section{Referências}

1. Brasil. Características e limites da Zona Costeira e Espaço Marinho [internet]. Brasília, DF: Ministério do Meio Ambiente, 2016 [cited 2016 Oct 9]. Available from: https://goo.gl/0AyuoJ

2. Amaral RCN. Cruzeiros marítimos. $2^{\text {nd }}$ ed. Barueri: Manole; 2006.

3. Ribeiro OCF. Os navios de cruzeiros marítimos enquanto campo de atuação profissional no lazer. LICERE [internet]. 2011 [cited 2017 Jun 27];14(1):1-18. Available from: https://seer.ufmg.br/ index.php/licere/article/view/509

4. Fraser TM. Human stress, work and job satisfaction: a critical approach. Genève: International Labour Office; 1983.

5. Castro AC, Vinagre RF. A percepção do tempo subjetivo e o estresse no trabalho offshore. Proceedings of XXIX Encontro Nacional de Engenharia de Produção; 2009 Oct 6-8, Salvador, BA.

6. Alvarez D, Figueiredo M, Rotenberg L. Aspectos do regime de embarque, turnos e gestão do trabalho em plataformas offshore da Bacia de Campos (RJ) e sua relação com a saúde e a segurança dos trabalhadores. RBSO [internet]. 2010 [cited 2017 Jun 27];35(122):201-16. doi: 10.1590/S030376572010000200004

7. Mendonça MA, Hora HRM, Costa HG. Qualidade de vida no trabalho (QVT) no setor petrolífero: um estudo comparando os trabalhadores onshore e offshore. Proceedings of XXXII Encontro Nacional de Engenharia de Produção; 2012 Oct 15-18, Bento Gonçalves, RS.

8. Leite RMSC. Bandeirantes do mar: a identidade dos trabalhadores das plataformas de petróleo. Rio de Janeiro: Intertexto; 2009.

9. Coelho LLV, Paparelli R. A experiência do trabalhador offshore: o caso de operadores de ROV. Proceedings of I Seminário de Saúde do Trabalhador de Franca; 2010 Sep. Franca, SP.

10. Seligmann-Silva E, Bernardo MH, Maeno M, Kato M. O mundo contemporâneo do trabalho e a saúde mental do trabalhador. RBSO [internet]. 2010 [cited 2017 Jun 27];35(122):187-91. doi: 10.1590/ S0303-76572010000200002

11. Castro AC, Nunes, DKP. Ações e relações entre gestão do conhecimento e estresse do petroleiro offshore. Proceedings of IV Congresso Nacional de Excelência em Gestão/CNEG; 2008 Jul 31-Aug 2. Niterói, RJ.

12. Goffman E. As características das instituições totais. São Paulo: Atlas; 1971.
13. Dupré A, Zocchio G. Fiscais flagram trabalho escravo em cruzeiro de luxo. Rep Bras [internet]. 2014 Apr [cited 2016 Oct 9]. Available from: https://goo.gl/vsEfb5

14. Iglesias EB. Bases teóricas que sustentam los programas de prevención de las drogas. Madrid (ES): Delegación del Goberno para Plan Nacional sobre Drogas;1999.

15. Lima, MEA. Dependência química e trabalho: uso funcional e disfuncional de drogas nos contextos laborais. RBSO [internet]. 2010 [cited 2017 Jun 27];35(122):260-8. Available from: https://goo.gl/ tYUN5A

16. Martis ERC, Zeitoune RCG. As condições de trabalho como fator desencadeador do uso de substâncias psicoativas pelos trabalhadores de enfermagem. Esc Anna Nery Rev Enferm [internet]. 2007 [cited 2017 Jun 27];11(4):639-44. Available from: http://www.scielo.br/pdf/ean/v11n4/ v11n4a13.pdf

17. Hine C. Internet research and the sociology of cyber-social-scientific knowledge. The Information Society [internet]. 2005 [cited 2017 Jun 27];21(4):239-248. doi: 10.1080/01972240591007553

18. Rocha PJ, Montardo SP. Netnografia: incursões metodológicas na cibercultura. Ver Assoc Nac Prog Pos-Grad Comunic [internet]. 2005 [cited 2017 Jun 27];2(22):1-22. Available from: https://goo.gl/ b8VT6Q

19. Kozinetz RV. Netnografia: a arma secreta dos profissionais de marketing: como o conhecimento das mídias sociais gera inovação [internet]. 2010 [cited 2017 Jun 27]. Available from: https://goo.gl/ TCoR $4 \mathrm{z}$

20. Pinto V, Neto CS, Costa MF, Bezerra FMP, Sobrinho HC, Cysne MRFP. Netnografia: uma abordagem para estudos de usuários no ciberespaço. Actas [internet]. 2007 [cited 2017 Jun 27];(9):1-10. Available from: https://goo.gl/jXhLKk

21. Herrera MH, Passerino LM. Estigma e ciberespaço: desafios da netnografia como metodologia para pesquisa em redes temáticas. RENOTE: Rev Novas Tecnol Edu [internet]. 2008 [cited 2017 Jun 27];6(2). Available from: http://hdl.handle. net/10183/29303

22. Brüggemann AL, Bitencourt FG. Cultura e tecnologias: netnografia com jovens futebolistas brasileiros na Europa. Proceedings of VII Congresso Sulbrasileiro de Ciências do Esporte; 2014 Sep 25-27; Matinhos, PR. 
23. Di Felice M, Torres JC, Yanaze LKH. Redes digitais e sustentabilidade: as interações com o meio ambiente na era da informação. São Paulo: Annablume; 2011.

24. Sifry D. State of the Blogosphere [internet]. San Francisco: David Sifry; 2005 [cited 2016 Oct 10]. Available from: https://goo.gl/AdFn3D

25. Recuero R. Weblogs, webrings e comunidades virtuais. Wired [internet]. 2003 [cited 2017 Jun 27];31. Available from: https://goo.gl/bo3rkX

26. BARDIN, Laurence. Análise de conteúdo. Lisboa: Edições 70, 1979.

27. Cerqueira C, Ribeiro LT, Cabecinhas R. Mulheres \& blogosfera: contributo para o estudo da presença feminina na rede. Ex Aequo [internet]. 2009 [cited 2017 Jun 27];(19):111-28. Available from: https:// goo.gl/PXfwfq

28. Abreu NR, Baldanza RF, Ribeiro GCG, Almeida NHS, Araújo AC. Estudo da percepção de gêneros sobre a comunicação em sites na internet. RAI: Rev Adm Inov [internet]. 2010 [cited 2017 Jun 27];7(2):60-79. doi: 10.5585/rai. v7i2.410

29. Castro AC. Produção offshore na Bacia de Campos (RJ): a perspectiva da psicologia do trabalho [internet]. 2013 [cited 2017 Jun 27];20(4):833-46. Available from: http://www.scielo.br/pdf/gp/v20n4/ aop_gp047511.pdf 